\title{
"JUGANDO CON LA MUERTE": ANÁLISIS COMPARATIVO DE UN MOTIVO MITOLÓGICO E ICONOGRÁFICO
}

\author{
Paola Corrente \\ Universidad del Pacífico \\ Giulia Degano \\ Universidad del Pacífico \\ Universidad Peruana de Ciencias Aplicadas
}

Recibido: $15-10-2016$

Aprobado: 22-1-2017

Paola Corrente es Licenciada en Letras Clásicas (Università degli Studi di Salerno, Italia), magíster en Antropología y doctora en Ciencias de la Religiones por la Universidad Complutense de Madrid, es profesora de Teología de las Religiones en la Universidad del Pacífico (Lima). Ha desarrollado parte de su investigación doctoral en Harvard y Oxford.

Es especialista en mitología, religión y literatura comparada del mundo mediterráneo antiguo, en particular Grecia, Mesopotamia y Levante.

p.corrente@up.edu.pe

Giulia Degano es Magíster en Historia del Arte y Conservación de los Bienes Artísticos y Arquitectónicos por la Universidad de Udine, Italia. Es profesora de Historia del Arte del Departamento de Humanidades de la Universidad del Pacífico y de la Facultad de Arquitectura de la Universidad Peruana de Ciencias Aplicadas de Lima, Perú. Sus investigaciones se enfocan en las relaciones interdisciplinarias e interculturales entre arte occidental y arte latinoamericano.

g.degano@up.edu.pe

\section{RESUMEN}

Este texto presenta los primeros resultados de un análisis interdisciplinario de la literatura e iconografía del "juego con la muerte", a través de un estudio de su recurrencia y simbología en diferentes culturas del mundo.

Dada la amplitud del tema y el carácter pionero de esta investigación, se ha optado por un análisis comparativo de sus manifestaciones más llamativas desde la antigüedad hasta la actualidad. "Jugar con la muerte" es una acción que se halla en numerosas tradiciones, y representa a la vez el entretenimiento y el engaño. La comparación entre las representaciones de esta acción en diferentes contextos mitológicos e iconográficos permite usar una mirada tanto universal cuanto particular: en efecto, si bien la aspiración a explicar la muerte y la inmortalidad representen características innatas del ser humano, y resulten similares en sus formas de manifestarse, cada cultura reproduce estos deseos de manera peculiar, y a veces única.

Este tema constituye entonces un indicador valioso para el estudio intercultural de una de las mayores características del hombre, la tendencia a superar sus propios límites: en este caso, representando lo irrepresentable y comprendiendo lo incomprensible, la muerte.

Palabras clave: muerte, juego, mito, arte, cosmogonía 


\begin{abstract}
The purpose of this article is to present the first outcomes of an interdisciplinary analysis of myths and images that revolve around the topic of the "game with death", through the study of its existence and symbolism in different cultures all over the world.

Because of the theme's complexity and originality of this investigation, a comparative analysis of the iconographic and literary sources from antiquity up to recent years has been followed.

"Playing with death" is a topic found in several traditions, which seems to symbolize both, the entertainment and the deception.

The comparison of different mythological and iconographic contexts allow us to employ an approach which is at the same time universal and specific: even though the ambition to explain death and immortality is innate in humankind, and tends to be similar in its manifestations, every culture has its own manner of representing it.

This subject-matter is, hence, a valuable resource for the intercultural exam of one of the major characteristic of human spirituality, say, the long for surpassing boundaries: in this case, representing what is not possible to represent, and understanding what it is not possible to understand, death.
\end{abstract}

Key words: death, game, art, myth, cosmogony.

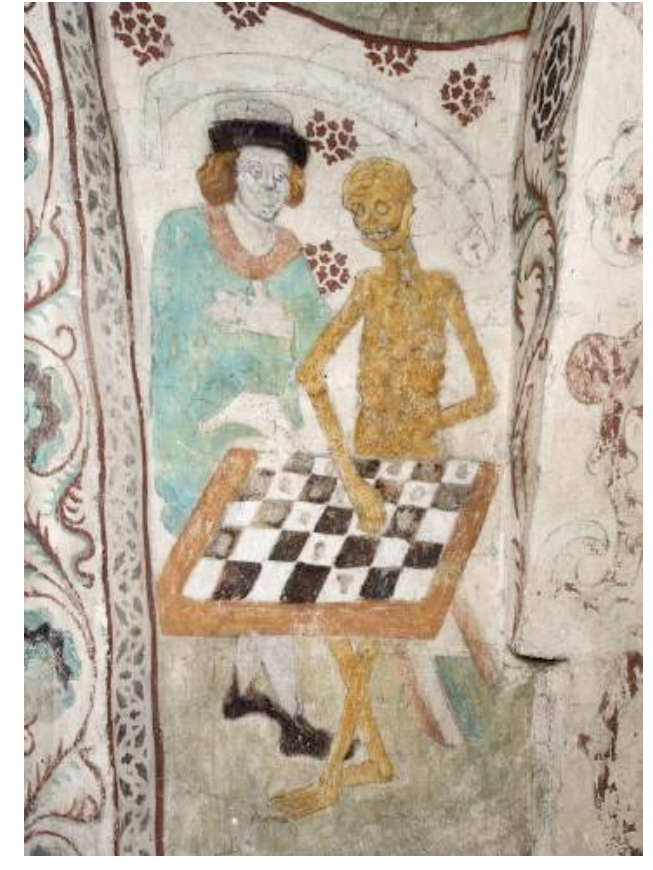

Fig. 1. Albertus Pictor.

Esqueleto jugando ajedrez con un hombre. 1480-1490. Täby kyrka. Suecia.

Foto: Caroline Levisse. (C) C. Levisse.

\section{INTRODUCCIÓN}

La idea para este artículo nace de una serie de reflexiones acerca de los mitos antiguos sobre el más allá despertados por la famosa película de Ingmar Bergman, El Séptimo Sello (1957), cuya acción se desarrolla mientras el protagonista, el caballero Antonius Block, juega al ajedrez con la muerte: este expediente narrativo y la escena final, en la que la muerte se lleva a los protagonistas al ritmo de una macabra danza, nos han llamado particularmente la atención.

Nos hemos preguntado, por un ladode dónde habrán podido llegar este motivo y esta iconografía a la tradición medieval europea, y, luego, qué tradiciones culturales han tratado estos temas $y$, por el otro, cuál era el significado que podían tener, al tratarse de un filme profundamente filosófico. 
Es cierto que las historias e imágenes del juego y la danza con la muerte son tratadas pocas veces de forma directa en la historia de la religión y del arte, y que, por lo general, es necesario hacer reflexiones más profundas para encontrarlas. A pesar de eso, el tema de la muerte es universal y la mitología de la muerte está bien desarrollada en todas las culturas, en las que la muerte, a menudo, representa uno de los poderes cósmicos más importantes y la divinidad que la personifica es una de las principales de los panteones antiguos.

Está claro que estamos en frente a un tema extraordinariamente amplio y complejo que aparece en varias culturas, en épocas y espacios diferentes.

Por lo tanto, en esta fase de nuestra investigación, hemos optado por un acercamiento comparativo a las fuentes mitológicas e iconográficas, sin ponernos límites geográficos o históricos, pues sería demasiado complicado intentar una reconstrucción genética de las manifestaciones que vamos a comentar; además, se necesitaría un grado de especialización muy profundo y vasto sobre culturas muy distintas.

La recolección de los datos nos ha llevado a algunas culturas en particular, la mesopotámica, la india o la mesoamericana, en las que nos detendremos, porque nos ofrecen los ejemplos más significativos para reconstruir e interpretar el imaginario de la muerte a lo largo de la historia.

\section{ICONOGRAFÍA Y MITOS}

Bergman elabora una película en torno a dos tipos de iconografías que tienen el mismo protagonista, la muerte, y que son el juego y la danza con la muerte.

Como él mismo explicó, trajo la inspiración para su película de un fresco de Albertus Pictor (1440-1507), pintor activo en Suecia en el 
siglo $\mathrm{XV}^{1}$, que forma parte de la decoración a fresco de la iglesia de Täby (Fig. 1). En él, podemos apreciar a un hombre jugando a ajedrez con un esqueleto, imagen que impresionó profundamente al director sueco y de que constituye la referencia directa de un tema que se configura como el leitmotiv de la cinta. Esta imagen se incluye dentro de un vasto y difuso conjunto de Danzas y Triunfos Macabros que caracterizan el panorama artístico de toda la Europa medieval. Como es sabido, la figura del esqueleto representa una "personificación" de la muerte y nos permite introducir un tema recurrente tanto en ámbito mitológico cuanto plástico, el de la muerte humanizada. Así representada, la muerte se vuelve una entidad cuya esencia oscila continuamente entre lo individual y lo universal, manifestando actitudes, pulsiones y sentimientos exquisitamente humanos.

No parece ser una casualidad que, al participar en el partido de ajedrez de Albertus Pictor, el hombre del fresco participe también -y tal vez quiera interferir- en esta ocasión de diversión para la muerte. La vestimenta del hombre, con su sombrero de pieles y su delicado atuendo turquesa, indica un estatus social elitista, que enfatiza el contraste, tanto moral cuanto posiblemente irónico, con el esqueleto. A través de las imágenes significativas como la del juego de mesa y la elegancia del oponente, el artista parece ironizar sobre la transitoriedad de la vida, de la fortuna, y, por consecuencia, de las riquezas materiales. De igual manera, el artista parece querer ironizar sobre la misma muerte, representándola como un esqueleto sonriente y entretenido en su juego con el hombre.

Bergman llegó a representar al mismo Albertus en la película, dedicándole una parte consistente en la cual el pintor reflexiona sobre la transitoriedad de la vida, que es uno de los temas fundamentales de este filme. En una escena describe el ciclo de frescos que está pintando al escudero Juan, y alude justamente al tema de la Danza de la Muerte que "danzando se lleva a todos". En las palabras del pintor, la representación no tiene otra función sino cumplir con la transmisión del mensaje moral apropiado al memento

\footnotetext{
${ }^{1}$ Albertus Pictor es uno de los pintores más famosos del Medioevo sueco, autor de importantes ciclos pictóricos a fresco como los de las iglesias de Härkeberga (1480) y de Täby (1480-1490), en la región de Uppland, cerca de Estocolmo.
} 
mori ${ }^{2}$, mensaje que se considera particularmente indicado para los tiempos apocalípticos que Europa está atravesando: estamos en los siglos XIV y XV y la peste negra está azotando el viejo continente dejando millones de muertos.

Efectivamente, a pesar de la amplia y variada manifestación del memento mori ya desde al menos la Antigüedad Clásica, nunca lo encontramos con tanta frecuencia como en el Medioevo.

Retomaremos mejor el tema del memento mori más adelante, por ahora hagamos una primera reflexión sobre esta llamativa y, en cierto sentido contradictoria, imagen de la muerte que danza: se trataría de una suerte de ritual catártico de humanización indispensable para una mejor asimilación de la acción inevitable de la muerte, que arrastra a la humanidad consigo a través de una estrategia inclusiva y lúdica (Fig. 2).

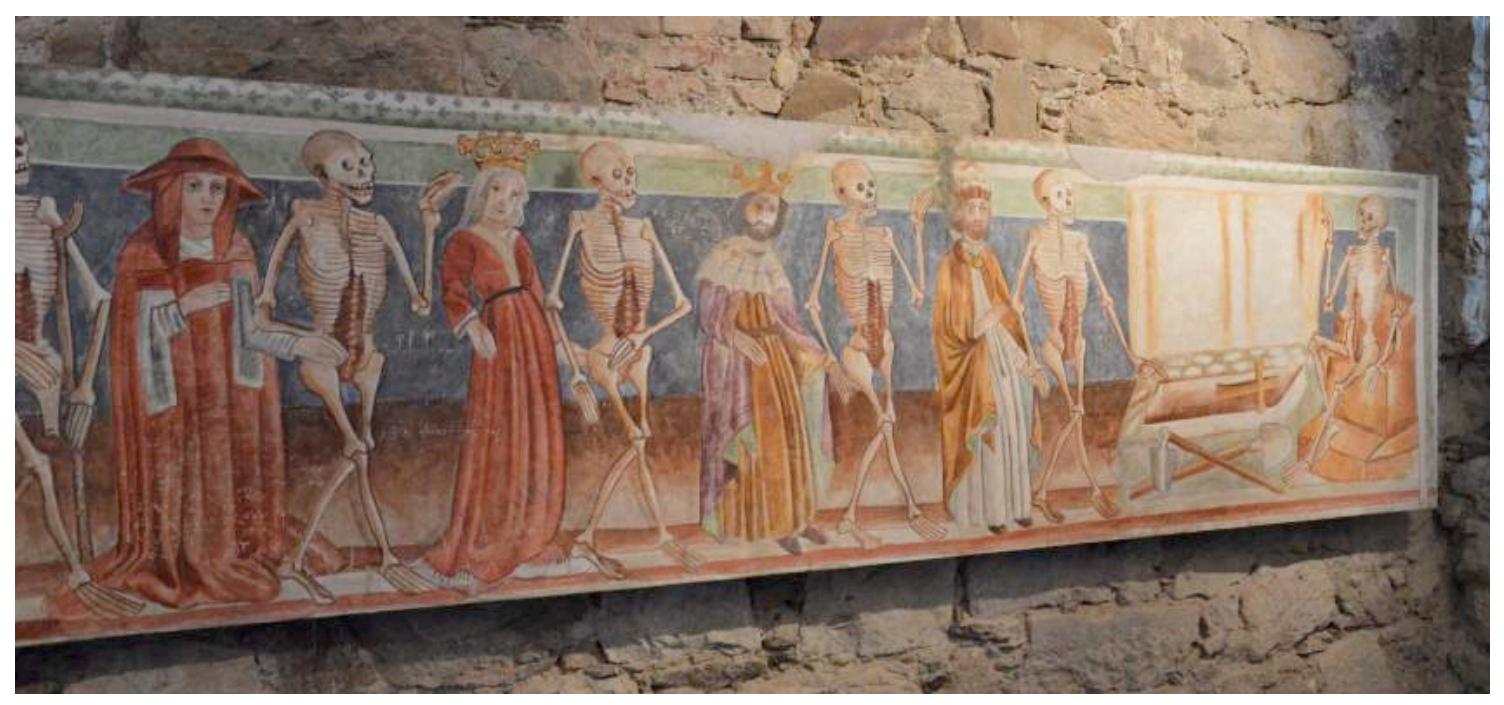

Fig. 2. Giovanni da Castua. Danza macabra. 1490. Hrastovlje. Eslovenia.

Foto: Giulia Deaano.

\footnotetext{
${ }^{2}$ Expresión latina, literalmente "recuerda que morirás". En el arte occidental, el memento mori es un tema recurrente con iconografías variadas, unidas por la imagen de la calavera o del esquéleto como alusión a la muerte, y, a veces, también de la rueda como alusión a la fortuna en vida, y que apunta a la fugacidad de la vida.
} 
La imagen de Albertus Pictor representa la primera manifestación de un tema iconográfico poco recurrente en la historia del arte, sobre todo si comparado con la difusión de los Triunfos y las Danzas de la muerte, temas que dominan el arte Medieval europeo hasta las primeras décadas del siglo XV.

Sin embargo, el carácter lúdico relacionado a la Danza macabra, que todavía se manifiesta en algunos casos tardíos como en los frescos realizados por Niklaus Manuel (1484-1530) para el Convento Dominico de Berna (1519)³, se irá perdiendo progresivamente.

El tema del Triunfo de la Muerte sobre las vanidades del hombre será más frecuente que la Danza en la época barroca. En particular, en las escuelas española y alemana, después de la Reforma ${ }^{4}$ los sujetos macabros parecen perder este rasgo casi burlesco, para enfatizar una condena moralizante de la vanitas, tanto física como intelectual, como en los célebres Embajadores (1533) de Holbein el Joven (1497-1543) ${ }^{5}$ o en el caso barroco de Juan de Valdés Leal (1622-1690) ${ }^{6}$ con sus Jeroglíficos de las Postrimerías (1672). Incluso una obra manifiesto de la Secesión vienesa de inicios de Novecientos, Muerte y Vida de Gustav Klimt (1862-1918), indica la prosecución de una tendencia que privilegia una representación dramática de la muerte. Solamente la caricatura grabada mantendrá, entre los siglos XVIII y XX, el gusto irónico para la representación de la muerte, como prueba el famoso

\footnotetext{
${ }^{3}$ Perdidos en el siglo siguiente, tras la destrucción del convento, estas representaciones cómicas sobreviven gracias a las acuarelas de Albrecht Kauw (mitad del siglo XVII). En ellas podemos apreciar a la Muerte, otra vez representada como esqueleto, burlándose de las vanidades de hombres y mujeres de diferente estatus social e intelectual, anulando así su valor: es un moderno caso de memento mori.

${ }^{4}$ En los años veinte del siglo XVI inician los movimientos de renovación del cristianismo a los que se da el nombre de Reforma Protestante. El comienzo oficial de la reforma es el 31 de octubre de 1517, cuando el monje agustino alemán Martín Lutero clava sus 95 tesis en la puerta de la iglesia del castillo de Wittenberg. La Iglesia responderá a las numerosas instancias reformadoras con el Concilio de Trento (1545-1563) y la llamada Contrarreforma, con la que establece las pautas a seguir para la renovación de la rama católica del cristianismo.

${ }^{5}$ Pintor y grabador alemán, hijo de Hans Holbein el Viejo (1465-1524). Gran retratista, es activo entre Suiza e Inglaterra.

${ }^{6}$ Pintor emblemático del barroco sevillano, famoso por sus alegorías moralizantes.

7 Pintor austriaco líder de la Secesión Vienesa (movimiento artístico surgido en Viena entre el fin del siglo XIX y el principio del $X X$ ) conocido por sus temas simbolístas y su estilo sinuoso y decorativista. La obra citada pertenece a su etapa madura, en la cual el artista confirma su gusto por la alegoría macabra y la contraposición eros-thanatos (= amor -en el sentido erótico- y muerte).
} 
caso de las caricaturas de Guadalupe Posada (1852-1913) ${ }^{8}$, expresión de un humor negro de origen ancestral en México, como veremos más adelante.

La interpretación del juego y de la danza con la muerte parece bastante clara: ambas apuntan a la fugacidad de la vida y la imparcialidad de la muerte. Sobre todo en la danza, estos aspectos son muy evidentes ${ }^{9}$. La muerte es personificada por esqueletos que bailan junto con una variada humanidad: ricos y pobres, jóvenes y ancianos, nadie se puede sustraer a la obligación de danzar con la muerte. El arte de la danza, así como el de la música, funciona como elemento de cohesión y también de anulación jerárquica y de burla social, al par del rol uniformador propio de la muerte. Esta representación, menos dramática con respeto a los Triunfos de la muerte, se puede incluir dentro de las imágenes relacionadas con los conceptos de juego y fortuna, y, por ende, de la implicación impredecible y repentina de la departida. No obstante, es importante tener en cuenta también el contexto histórico preciso que hemos mencionado antes, ya que la pandemia de la peste tuvo un enorme impacto en el imaginario popular, que se volvió casi obsesivo con la muerte.

Procediendo atrás en el tiempo y reseñando varias culturas del mundo, llama la atención que la iconografía del juego con la muerte está presente solo en algunas tradiciones culturales, por ejemplo, la egipcia y la americana; en determinados casos podemos contar también con el suporte de la mitología, que conserva historias sobre estos temas.

En particular, en Egipto encontramos un equivalente de la pintura medieval de Albertus Pictor, pues en esta representación también estamos frente al tema del juego de mesa como expresión de una relación cotidiana con la muerte.

\footnotetext{
${ }^{8}$ Es el más famoso grabador mexicano, considerado como uno de los precursores de la modernidad artística del país. Inventor de la famosa caricatura "La Catrina (La Calavera Garbancera)", calavera vestida según la moda elegante de la época, que funciona tanto como memento mori dedicado satíricamente a la élite local.

9 Para profundizar el tema de la danza macabra se recomienda el ensayo de Gonález Zymla. (2014) En: la Revista Digital de Iconografía Medieval. Vol. VI (11): pp. 23-51.
} 
Se trata de un fresco sepulcral que procede de la tumba de la reina Nefertari ${ }^{10}$ (Fig. 3), que nos muestra a la difunta jugando con un oponente invisible, en un interior definido por la silueta de una habitación, al lado de la cual podemos ver la exquisita imagen del ba o alma de la difunta, representada como un rapaz con rostro humano. Evidentemente, la reina está jugando con la Muerte o con un espíritu del más allá, ya que este juego de mesa, el snt ${ }^{11}$, cuyo nombre remite a la acción de "pasar" de un lado al otro del tablero, requiere dos jugadores ${ }^{12}$, y la invisibilidad es una de las características que se le da a la muerte, por obvios motivos simbólicos.

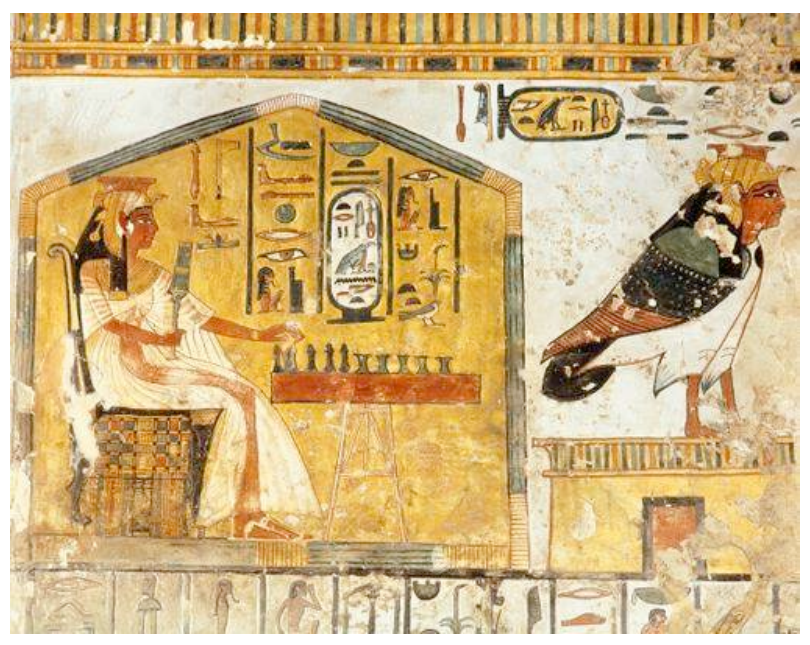

Fig. 3. Nefertari jugando a snt. Tumba de Nefertari. 1250-1255 a.C. Valle de las Reinas. Tebas. Egipto. (C) 2017 PBS \& WGBH Educational Foundation

Este era un juego entre los más populares del mundo egipcio, y maquetas de este juego se encuentran frecuentemente entre las ofrendas de la tumbas por su fuerte relación simbólica con el más allá ya que simula el camino que el difundo debe realizar para reunirse con $\mathrm{Ra}$, la divinidad del sol que, en este contexto, ha de ser entendida como símbolo del sol al ocaso. La meta, el recuadro final en el tablero (el número 30), está de hecho decorado con el símbolo del sol al ocaso: efectivamente, al fallecer, el hombre sube al barco de Ra para

\footnotetext{
${ }^{10}$ Neferetiry Meritenmut (1295-1255 a.C.), "Gran Esposa Real” de Ramses II, es la reina más famosa de la XIX dinastía del Nuevo Reino, conocida por la magnificencia de las obras artísticas y arquitectónicas que le han sido dedicadas, como su tumba monumental en Abu Simbel, Egipto.

${ }^{11}$ Para profundizar el tema se recomienda el artículo de Piccioni sobre este juego egipcio (1980) publicado en Archaeology 33 (Julio/Agosto 1980): pp. 55-58.

${ }^{12}$ Por ejemplo, parece que también en la tradición griega antigua, Hades, el dios del más allá (que era en origen la denominación del lugar mismo), deriva su nombre de la raíz *a-wid-, "invisible", "no visto".
} 
alcanzar el inframundo. En el tablero encontramos también el símbolo de "agua", elemento estrechamente relacionado con el más allá en las religiones antiguas, entre aquellos que preceden el número treinta. El símbolo (el de "las aguas del caos") corresponde justamente al momento de transición final representado por el viaje en el barco de Ra, y es asociado con aquellos de "peligro" y de "trampa", ya que los pecadores no podrán subir a él y permanecerán en dichas aguas. La imagen de la reina jugando ajedrez seguida por aquella de su ba, se refiere, además, al capítulo diecisiete del Libro de los Muertos ${ }^{13}$ en el cual el juego del snt es descrito como una ocupación que permite al alma del difunto transfigurarse, transformándose en un ave rapaz, seguidor de Osiris ${ }^{14}$, para salir de la necrópolis y quedarse en el mundo de los vivos durante el día.

Además, al mundo egipcio remonta un mito que trata el tema del juego con la muerte y que nos ha llegado en la redacción del historiador griego Heródoto (siglo $\vee$ a.C.) que, en el segundo libro de sus Historias, cuenta que el rey Rampsinito había bajado, vivo, al más allá, donde había jugado con alterna fortuna a los dados con Deméter, y que había vuelto a la tierra llevando una toalla de oro como don de la diosa ${ }^{15}$. Como suele hacer, Heródoto sincretiza las divinidades helenas y las egipcias y, también en este pasaje, llama con el nombre de una destacada diosa griega, Deméter ${ }^{16}$, o bien a una diosa del más allá egipcio, o se está refiriendo a la importantísima diosa egipcia Isis ${ }^{17}$, con la que ya en otros pasajes

\footnotetext{
${ }^{13}$ Nombre moderno bajo el cual se reúne una colección de manuscritos, organizada en 175 capítulos, que contienen textos sobre rituales relacionados con el más allá egipcio. En: Book of the Dead, University College, London 2002. Dirección: http://www.ucl.ac.uk/museumsstatic/digitalegypt/literature/religious/bdfront.html

${ }^{14}$ Una de los principales dioses del antiguo Egipto, Osiris era el señor de los muertos y del más allá, hermano y marido de Isis, otra grande entre las divinidades egipcias (véase la nota 17) protagonista de un reconocido mito en el que, una vez asesinado por su hermano, el malvado Seth, recuperaba la vida gracias a las artes mágicas de su esposa.

${ }^{15}$ Her. Hist. 2, 122.

16 Deméter es una de los doce olímpicos, las divinidades mayores de la religión de la Grecia antigua. Hermana de Zeus, Hades, Poseidón y Hera, es la diosa de los cereales y de la cosecha, estrechamente relacionada en el mito y en el rito con su hija Perséfone y nota por los eventos de la historia del rapto de la joven a manos de Hades. Con la hija fue la figura central de los misterios eleusinos.

17 Isis, esposa de Osiris y madre de Horus, fue una poderosa diosa-madre asociada con la naturaleza y experta en las artes mágicas. Su fama fue tanta que, en la tarda antigüedad, fue
} 
había identificado a Deméter ${ }^{18}$; las dos tienen conexiones con el Más Allá.

Por lo que tiene que ver con la tradición mesoamericana, el elemento del juego con la muerte tiene un rol fundamental en una de las narraciones más reveladoras de la cultura maya, el Popol Vuh ${ }^{19}$, un texto colonial cuyo manuscrito original, ahora perdido, remite al contexto guatemalteco de Santa Cruz del Quiché y a una datación que oscila entre 1554 y $1558^{20}$. Se trata de una transcripción del maya quiché al latín de una antología mitológica, realizada por miembros anónimos de la élite local poco después de la caída de Cumarcah, antigua capital de los mayas quiché, en mano a los españoles, que fue conservada en la ciudad guatemalteca de Chichicastenango hasta que, a inicios del siglo XVIII, el monje dominico Francisco Ximénez, pionero en los estudios sobre la lengua quiché, se enteró del manuscrito y obtuvo el permiso para copiarlo. El texto manifiesta distintas influencias culturales, mezclando la maya predominante con elementos de la tradición tolteca-mexica ${ }^{21}$ y cristiana.

Este texto es de particular interés para nuestro estudio en cuanto relata como los Gemelos Divinos (Fig. 4), figuras recurrentes en la mitología maya, logran engañar y vencer a los señores del más allá, los Xibalbas. La historia es organizada en dos partes, cada una protagonizada por una pareja distinta de Gemelos Divinos, que corresponde la primera a los padres que desafían a los señores de Xibalba y la segunda a los hijos que se encargan de vengar su muerte, a su vez desafiando y derrotando a los Xibalbas. En ambas historias, la relación con el más allá empieza con un partido de juego de pelota entre los Gemelos Divinos que molesta los dioses del inframundo, dado que el campo se ha construido por encima del

venerada incluso fuera del territorio egipcio y el culto mistérico alrededor de su figura floreció en todo el Mediterráneo.

${ }^{18}$ Her. Hist. 2, 42 ss.

19 Popol Vuh significa "libro de la comunidad" y es un título convencional que se le dio a la composición cuando se transcribió.

${ }^{20}$ Una óptima edición del Popol Vuh, traducida y comentada, es la de Christenson (2007).

${ }^{21}$ La tolteca y la mexica (más conocida como azteca) son culturas precolombinas, respectivamente del periodo Clásico (siglos III-XI d.C.) y Posclásico (XI-XVII d.C.), que dominaron el Altiplano Central hasta la llegada de los españoles, y que tenían por capitales Tollan-Xicocotitlan (actual Tula de Allende), la primera, y Tenochtitlan (actual Ciudad de México), la segunda. 


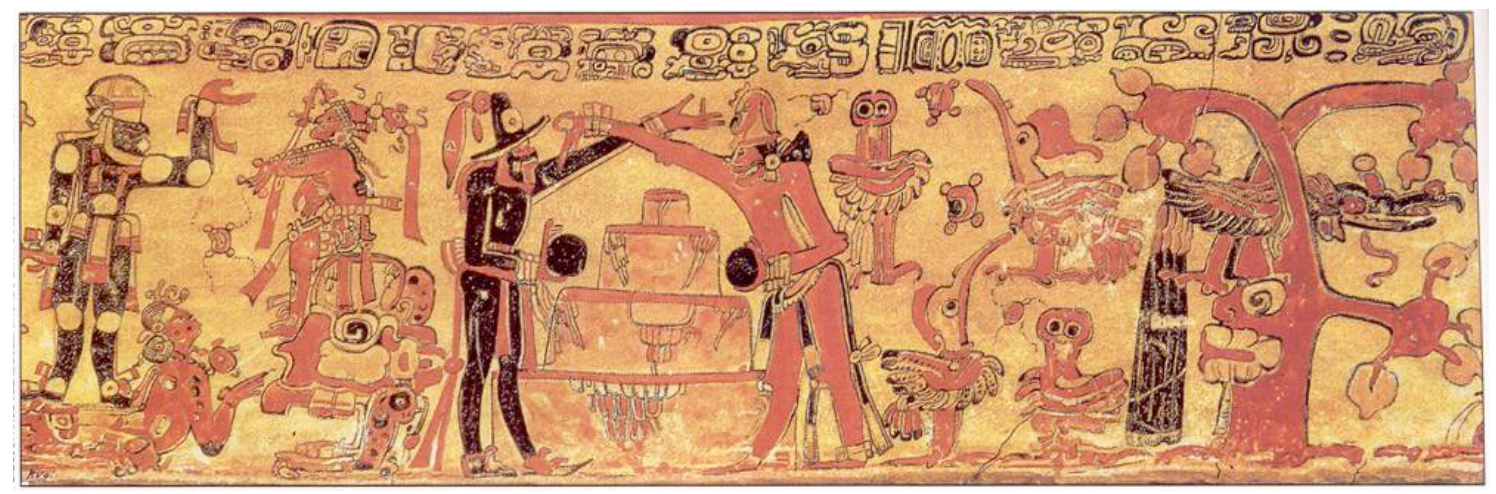

Fig. 4. Juego de pelota con Hun Hunahpú y viaje a Xibalbá. (c) Justin Kerr. No. K1288.

camino que lleva al más allá. Los dioses invitan a los gemelos a su reino para castigar su impiedad, desafiándolos al mismo juego y provocando su muerte con el engaño. Sus hijos, los gemelos Hunapu y Xbalanque, si bien derrotados por los Xibalbas en primera instancia al mismo juego de pelota, resucitan milagrosamente en forma de dos pobres huérfanos notorios para su habilidad en entretener con danzas y trucos. Su fama les permite ser invitados por los Xibalbas al más allá. Los gemelos, después de haber ganado la confianza y admiración de los dioses del más allá con sus trucos, logran provocar la participación espontánea de uno de los dioses principales, Uno y Siete Muerte, en un truco en el cual se sacrifica a un ser y se le devuelve la vida. Uno de los dioses, entusiasta, se propone para probar el truco, cayendo en el engaño de los gemelos, que los sacrifican pero no les devuelven la vida: en un revolqué de roles, el castigo ahora deriva de los héroes.

Hasta aquí hemos visto que varias culturas, que difieren entre ellas por nivel de desarrollo, cronología y ubicación geográfica, tratan las mismas temáticas y que, por otro lado, este tipo de iconografía y de mito parece ausente en algunas de las principales civilizaciones del mundo antiguo, como por ejemplo Grecia.

No obstante, la situación cambia si profundizamos más en la simbología de estas imágenes y de los mitos que las acompañan.

Empecemos con el juego. En nuestros mitos e imágenes hemos visto que hay de dos tipos, el ajedrez y el juego de pelota. En el mundo antiguo, en general, los juegos de mesa y los juegos con una pelota 
eran dos formas de juego muy conocidas. Cualquier tipo de juego de mesa parecido al ajedrez o a los dados era muy común, porque varios objetos fáciles de procurarse, como las piedras, podían hacer la función de los dados o de los peones. El tlachtli mexica era un deporte parecido al fútbol, juego propio de las civilizaciones mesoamericanas, en el cual los jugadores golpeaban una pelota utilizando su cadera, codos y rodillas para que la bola se mantuviera en juego, sin caer en el piso, y entrara en un estrecho aro de piedra colocado a la mitad del campo de la cancha ${ }^{22}$. Por su parte, parece que los griegos y romanos practicaban juegos parecidos al hockey y al rugby, mientras que la literatura registra la costumbre de otro juego difundido en Mesopotamia en épocas mucho más antiguas. En el poema sumerio llamado Gilgamesh, Enkidu y el Más Allá ${ }^{23}$, el gran rey de Uruk ${ }^{24}$, el semidivino Gilgamesh, se construye dos juguetes con los que él y los hombres de Uruk juegan un agotador juego que los tienes ocupados por días enteros. No hay acuerdo entre los estudiosos sobre qué juguetes son estos, y normalmente se suele traducir las palabras sumeria mikku y pukku, que los indican, como "pelota" y "mazo" (también "aro" y "palo"), a indicar los instrumentos necesarios para un juego que, en falta de noticias más ciertas, podríamos pensar similar al croquet o al cricket.

Hay también otra dimensión del juego que merece la pena analizar, porque nos lleva a algunas reflexiones muy sugestivas para nuestra

22 El tlachtli era un juego fuertemente ritual: el movimiento de la pelota representava el movimiento de los astros en el cielo y, en especial, la derrota del Sol sobre su hermana Luna al amanecer, y, por extención, de la vida sobre la muerte. Un campo de juego de pelota figuraba en cada centro mesoamericano que superase la entidad de pueblo. La importancia del juego era tal que servía también para predecir el futuro, en base al resultado y a los signos, fastos o nefastos, que se manifestaban durante el partido.

${ }^{23}$ También se lo conoce como Bilgames y el Más Allá: 'En aquellos días, en aquellos días lejanos', siendo Bilgames la variante del nombre Gilgamesh que el rey toma en el sumerio de estas composiciones, y 'En aquellos días, en aquellos días lejanos' los versos iniciales. Se trata de historias sobre el rey Gilgamesh paralelas a las recogidas en la famosa Epopeya de Gilgamesh, una de las obras más antiguas de la historia de la literatura, cuya versión estándar está constituida por doce tablillas, escritas en acadio, del II milenio a.C.

${ }^{24}$ Una de las primeras e importantísima ciudad en el sur de Mesopotamia y centro de veneración de la gran diosa Inanna/Ishtar. De esta diosa hablaremos más adelante. Para el texto del poema sumerio, véase la base de datos on-line ETCSL de la Universidad de Oxford: http://etcsl.orinst.ox.ac.uk/cgi-bin/etcsl.cgi?text=c.1.8.1*\#. En: George, A. (1999) The Epic of Gilgamesh. London, el autor recoge tanto la versión acadia del Gilgamesh, como los poemas sumerios. 
investigación. Sobretodo en la mentalidad occidental, al juego no se le reconoce ninguna validez o ninguna base real, porque pertenece a la esfera de la ilusión e implica el engaño. Sin embargo, en el ámbito religioso y mitológico antiguo, el juego se introduce en muchas ocasiones, tanto rituales ${ }^{25}$ como mitológicas, y tiene un significado serio, a menudo relacionado con la cosmogonía, o sea, tiene que ver con la creación. Si seguimos este significado del juego, nos encontramos con varios ejemplos que conectan el juego directamente con la muerte, una relación en la que ya el mito maya hacía hincapié: en efecto, el tlachtli engloba una significación cosmológica, al representar la luche entre día y noche, vida e inframundo.

A tal propósito, el caso de la mitología mesopotámica ${ }^{26}$ es particularmente interesante, porque en los mitos en los que uno de los protagonistas es Ereshkigal, la diosa de la muerte, el engaño es bastante frecuente. Haremos dos ejemplos sobre todos. En el mito Ereshkigal y Nergal, en el que se relata de cómo Nergal ${ }^{27}$ se convierte en el esposo de la diosa y en el señor del más allá ${ }^{28}$. Ereshkigal,

${ }^{25}$ Podemos pensar en los juegos fúnebres, por ejemplo, o en las mismas Olimpíadas, los juegos panhelénicos que tenían lugar cada cuatro años en la ciudad de Olimpia y que se hacían en honor del primer de los dioses griegos, Zeus.

${ }^{26}$ La literatura de la antigua Mesopotamia está escrita en sumerio y acadio, dos lenguas habladas por pueblos que se asentaron en el país en épocas distintas. Los sumerios poblaron las zonas meridionales de Mesopotamia anteriormente a los acadios, pero con el tiempo su lengua dejó de ser hablada y sobrevivió como lengua literaria. Por eso, de un mito podemos tener versiones en ambas lenguas, y a veces, el acadio es una traducción del texto sumerio. Por lo que tiene que ver con las divinidades protagonistas de los mitos, ya que hubo sincretismo entre el componente sumerio y el acadio en su carácter divino, es norma indicarlas con el nombre en las dos lenguas: por ejemplo, a propósito de las divinidades que estamos tratando aquí, Inanna es el nombre sumerio e Ishtar, el acadio; Enki es el sumerio y Ea, el acadio; An es sumerio y Anu es acadio; los nombres de Ereshkigal y Nergal se mantienen invariados en las dos lenguas. Para mayor información sobre los dioses mesopotámicos de los que hablamos, véase el diccionario Black, J. y A. Green. (1992) Gods, Demons and Symbols of Ancient Mesopotamia. Austin.

27 Como muchas de las divinidades sumero-acadias, Nergal es una figura compleja. Recordado principalmente como el señor del más allá esposo de Ereshkigal, tenía también otras características, relacionadas en primer lugar con las enfermedades y la guerra, y por eso se identificaba a menudo con otro dios, el violento Erra.

${ }^{28}$ Existen dos versiones de este mito, escrito en acadio, de finales del II milenio a.C., del cual no disponemos de una versión en sumerio, una más larga y más antigua, la babilonia estándar, y la que fue hallada en la antigua ciudad egipcia de Amarna. El mito cuenta que Ereshkigal, que no puede ir al cielo para participar en el banquete que los dioses han organizado, envía a su visir Namtar a recoger su parte de comida. A la llegada del emisario infernal, todos los dioses aparte Nergal se levantan y hacen una reverencia para saludarlo: este es el episodio que suscita la ira de 
enfurecida con él porque le ha faltado de respeto, quiere arrastrarlo al más allá para que pague con la vida su afrenta, mas el dios consigue "escapar" la muerte seduciéndola. En este mito, el engaño a los daños de la diosa/muerte aparece en más de una ocasión. Después de haber sido su amante por seis días, Nergal quiere regresar al cielo y, para salir del más allá, ha de estafar al portero, para que le abra la puerta (le dice que tiene que llevar un mensaje al dios Anu por parte de Ereshkigal) y, finalmente, cuando ha regresado al cielo y Ereshkigal se ha percatado de su engaño y envía Namtar a recogerlo, el dios $\mathrm{Ea}^{29}$ altera su semblante para que el visir no lo reconozca: lo hace calvo, cojo y con un tic. Y, en efecto, Namtar no se da cuenta que este dios raro es en realidad Nergal y regresa al más allá sin cumplir las órdenes de su señora.

Podríamos citar también el mito del descenso al más allá de Inanna/Ishtar ${ }^{30}$. En el Descenso de Inanna, Inanna, poderosa señora de la guerra y del eros ${ }^{31}$, decide quitarle el reino a su hermana y va al más allá pero, para entrar, intenta un engaño cuando le dice a Neti, el portero, que ha venido para atender el funeral de su cuñado ${ }^{32}$.

la diosa que quiere vengar esta ofensa. Las dos versiones del mito presentan varias diferencias en la narración, por ejemplo, sobre cómo Ereshkigal y Nergal acaban casándose: en la babilonia, los dos dioses empiezan una relación amorosa, en la de Amarna Nergal amenaza a Ereshkigal y ella, para evitar que la mate, le ofrece el reino del Más Allá y el matrimonio. Para el texto completo del mito y un buen comentario, véase Foster, B. (2005) Before the Muses. An anthology of Akkadian Literature. Bethesda: pp. 506-524.

29 Enki/Ea es uno de los dioses más importantes de Mesopotamia, señor de las aguas y divinidad hábil e inteligente, siempre dispuesta a ayudar a los otros dioses y a los hombres. Enki/Ea lidera el panteón mesopotámico en una tríada con otros dos dioses, que también mencionaremos en este trabajo: Enlil, el señor de los vientos y Anu/An, personificación del cielo.

${ }^{30}$ De este hermoso mito existen dos versiones, una en sumerio, más larga y completa, (El descenso de Inanna al más allá) y una en acadio (El descenso de Ishtar al más allá), que, aparte de la notable diferencia en la extensión, discrepan en varios puntos. En este párrafo, tendremos en cuenta la versión sumeria del mito, pues los particulares que estamos comentando no aparecen en la misma forma en el texto acadio.

31 Hija de Nanna/Suen, el dios de la luna, y parte de la generación de los dioses "jóvenes", con Ereshkigal, Nergal y varios otros (como Ishkur/Adad, Utu/Shamash y Ninurta, que son sus hermanos o hermanastros, ya que el parentesco de todos cambia en los diferentes mitos, y la misma Inanna/Ishtar es considerada hija de Enlil, de Anu/An o de Enki/Ea), Inanna/Ishtar fue probablemente la figura más preminente entre los dioses mesopotámicos a lo largo de toda la historia mitológica del país, protagonista de múltiples historias, algunas de las cuales incluso la ven quitarles el poder a los tres grandes dioses Enki/Ea, Enlil y Anu/An.

32 Desc. In. vv. 85-89. Para el texto entero del mito sumerio, véase ETCSL: http://etcsl.orinst.ox.ac.uk/cgi-bin/etcsl.cgi?text=t.1.4.1\#, mientras que para la versión acadia se puede consultar Foster, B. (2005): pp. 498-505. 
Si volvemos al juego como deporte, también encontramos una conexión con la muerte, que se hace muy evidente en las tradiciones mexica y maya, porque, al parecer, el juego de pelota preveía que los perdedores fueran sacrificados, pero que aparece igualmente en los menos cruentos juegos de mesa que hemos mencionado. Asimismo, si reflexionamos sobre las aventuras de Gilgamesh que hemos visto arriba, por más que estos pasajes son de difícil traducción e interpretación, retorna este vínculo entre juego y muerte. En el relato, en efecto, el juego acabará mal, ya que el mekku y pukku caen al Más Allá, lo cual provoca la desesperación de Gilgamesh por haberlos perdido y el sacrificio de su fiel amigo Enkidu que se ofrece ir al recuperarlos para que el rey se tranquilice: en el intento de recogerlos, Enkidu queda atrapado en el más allá, eso es, muere.

Había otro juego muy difundido en el mundo mediterráneo antiguo que nos puede interesar, el de los astrágalos. De probable origen oriental, como en general se piensa para los juegos de mesa, aparece a menudo en las representaciones de vida cotidiana en Grecia y Roma. El juego de los astrágalos parecía tener una dimensión "obscura" toda suya, por varias razones: los astrágalos han sido hallados en las tumbas ${ }^{33}$; este juego es un sujeto pictórico de estelas sepulcrales del período orientalizante (siglos VIII-VII a. C.) y los relieves funerarios de época romana (III siglo a. C.) y los astrágalos, precursores de los dados, generalmente estaban hechos de huesos (tarsos de ovinos en especial). Sobre este último aspecto volveremos más adelante.

A este punto, surgen dos preguntas: ¿por qué se engaña a la muerte?

$Y$, ¿es posible engañar a la muerte?

Por lo que concierne la primera pregunta, en el mito de Nergal, Enki ha conseguido solo retrasar el momento de la muerte del dios, pero no evitarla: Nergal será descubierto y traído de vuelta al más allá, donde se quedará definitivamente.

\footnotetext{
33 Esto podía reflejar, también, una dimensión "cotidiana" del más allá: después de haber muerto, la gente seguía haciendo las mismas cosas que había hecho en vida. También el juego egipcio snt, recordemos, ha sido encontrado en tumbas.
} 
En el mito de Inanna/lshtar, la diosa, al entrar al más allá, muere y Enki/Ea interviene para salvarla: crea unos seres mágicos (en la redacción acadia es un ser solo, en la sumeria son dos) que envía al más allá recomendándoles que alaben a Ereshkigal para que, en gratitud, les ofrezca lo que quieran: ellos querrán el cadáver de Inanna/Ishtar, que así volverá a la vida.

Podemos hacer una primera reflexión: cuando a intentar el engaño son divinidades mayores del panteón, como efectivamente lo son Inanna/Ishtar y Nergal, estas logran sus objetivos. Los dos dioses querían sobrevivir a la muerte, $y$, como son dioses sumamente importantes, no pueden quedarse muertos en el más allá. Por eso, Inanna/Ishtar consigue burlarse de las leyes del más allá y regresa, aunque obedeciendo a otra ley universal, que es que nadie puede dejar el infierno sin dejar a alguien en su lugar: ofrecido el reemplazo, la diosa se puede quedar en la tierra. En cambio, Nergal se queda en el más allá porque es el dios de ese lugar: el mito del que es protagonista explica cómo de dios del cielo se convirtió en dios del inframundo: su destino divino es estar allá. En esto, Nergal ofrece un paralelo con la mitología maya. En este caso también, el mito de los gemelos es un mito de fundación: los gemelos, en realidad, establecen las reglas de culto del más allá y el status mismo de este reino, cuyos dioses y habitantes serán desde este momento considerados inferiores a los del cielo y de la tierra.

Lo interesante en todos los ejemplos es que los protagonistas imponen su voluntad, temporalmente o no, solo estafando al dios de la muerte. Esto se debe al carácter del politeísmo. Aquí los dioses no tienen atributos absolutos, es decir, que no existe algo parecido a un dios todopoderoso, sino que los poderes de una divinidad están limitados por los de otra: Inanna/lshtar, Nergal o Enki/Ea no pueden ganar a Ereshkigal con sus poderes, porque ella es una diosa tan importante como ellos, solo pueden conseguir vencerla a través de una estafa.

Naturalmente, los mismos criterios no aplican para los seres humanos. En su caso, no es posible que ganen a los dioses de la muerte, ni siquiera con el engaño $y$, cuando los seres humanos consiguen regresar desde el más allá, esto pasa más bien por una 
concesión de los dioses: lo hemos visto con Rampsinito, al que Deméter concede regresar ( $y$, además, da un regalo), y podemos recordar el mito de Orfeo, el mítico cantor que obtuvo la posibilidad de llevarse a su esposa del Más Allá gracias a su música, cuya belleza había conmovido a Perséfone ${ }^{34}$. Hay una reflexión ulterior que podemos hacer a tal propósito. En el imaginario de las religiones y mitologías politeístas, el concepto de Más Allá es más bien borroso y variamente descripto: en general, es uno de los espacios en los que se divide el cosmos antiguo, el lugar (situado, por lo más, bajo tierra), regido normalmente por una de las divinidades principales ${ }^{35}$, al que los seres humanos van una vez que han muerto, que, si no es un sitio placentero en el que pasar la eternidad, tampoco es un lugar de penas y no equivale a la idea de infierno, purgatorio y paraíso a la que nos han acostumbrado las religiones monoteístas ${ }^{36}$. En el más allá griego, entre los únicos que padecen un castigo, está Sísifo, el astuto rey de Corinto, culpable de haber engañado a los dioses del más allá para sustraerse a la muerte ${ }^{37}$.

Finalmente, podemos hacer otras dos observaciones que encajan con este discurso. En la mitología mesopotámica, parece que Ereshkigal y Nergal deciden si alguien tiene que morir en el

\footnotetext{
${ }^{34}$ El mito de Orfeo, que fue muy conocido en el mundo antiguo y que tuvo muchísimo éxito en las artes de las épocas siguientes, es contado por varios autores, entre los cuales los poetas latinos Virgilio (Georg. 4.453-525) y Ovidio (Met. 10.1-11.84).

${ }^{35}$ Como en otras culturas, en la mitología griega, los señores del más allá son Hades y Perséfone: en particular Hades, hermano de Zeus, es uno de los grandes dioses helenos. Sin embargo, existe la figura de Thanatos, un genio alado que podemos considerar un emisario de los dioses infernales, que va a recoger a los muertos. Su nombre, en griego, significa "muerte" y es, por lo tanto, una personificación de la muerte y su figura es más cercana a la representación "popular" de la muerte que estamos viendo en particular en las imágenes. Es interesante notar que también en la mitología de Grecia, si los dioses del más allá Hades y Perséfone no pueden ser estafados por la sacralidad misma de su rol divino, sí es posible que las figuras inferiores, como Thanatos, puedan ser controladas, por así decirlo. Hay dos mitos famosos en los que Thanatos es subyugado por el infido Sísifo, que conoceremos en seguida, que lo ata impidiendo así que la gente muera, y por el mayor de los héroes griego, Heracles que, en la tragedia Alcestis de Eurípides lo obliga a devolver a la mujer que estaba llevando al más allá.

${ }^{36}$ Para una descripción del más allá en las tradiciones griega y próximo-orientales, véase Corrente, P. (2012) Dioniso y los dying gods: paralelos metodológicos. Madrid (Tesis Doctoral): cap. 4.3. En: Publicación on-line de la Universidad Complutense de Madrid: http://eprints.sim.ucm.es/18071/

${ }^{37}$ Hay varias versiones del mito de Sísifo. Los otros compañeros del rey en el atroz destino en el más allá son Tántalo, Ixión, Titio y Licaón, que, como él, habían intentado contravenir a las leyes universales y eternas y habían ofendido a los dioses. Como acontece a menudo, hay varias versiones también de los mitos de estos personajes. Para las fuentes, véase $O C D$, s.v. Tantalus, Ixion, Lycaon, Tityus y Sisyphus.
} 
momento en que la persona llega delante de ellos: aquí, de hecho, el más allá funciona como una ciudad ${ }^{38}$, y el muerto está realmente muerto solo cuando el escriba apunta su nombre en una tablilla con el elenco de los residentes del más allá, sancionando así su muerte. Por lo tanto, la idea de "jugar" con la muerte, en el sentido de distraerla o engañarla porque existe la posibilidad que se pueda influenciar su decisión y evitar así la condena a muerte, tiene mucho sentido. Y que existiera esta tendencia a engañar con la muerte parecería evidenciado por otro particular de los mitos mesopotámicos: para arrastrar a los futuros "muertos", Ereshkigal usa un tropel de demonios, los galla, que vagan por la tierra en búsqueda de víctimas (los mismos que acompañan a Inanna/Ishtar para que entregue a un sustituto y que aparecen en varios mitos sumerios y acadios sobre el Más Allá): ¿será posible que estos demonios actúen de policías para Ereshkigal porque ella a veces es fácilmente víctima de trampas?

Y si miramos a otras culturas, hallaremos como común la tendencia de los dioses principales a engañar, jugar o apostar con otros dioses: incluso en la historia bíblica de Job ${ }^{39}$, hay una implícita referencia a una apuesta entre Yahveh y Satán (Jb. 1:6-12), y, en la tradición cristiana, Satán está siempre "jugando" con Dios para obtener las almas de los hombres (Hiltebeitel 2005: p. 3263). Asimismo, en muchas mitologías, en especial en las americanas, existe el trickster, una figura divina o sobrenatural, que tiene a menudo el aspecto de un animal, y que es descrita en tonos cómicos. Este "tramposo", este "bribón" divino, astuto y amoral, con sus acciones, estropea la creación de los otros dioses y, de esta forma, crea a su vez: por

\footnotetext{
${ }^{38}$ Una de las palabras acadia con las que en los mitos mesopotámicos se hace referencia al más allá es urkallu, que significa, precisamente, "gran ciudad" y el nombre de Nergal significa "señor gran ciudad". En el más allá mesopotámico los dos dioses que reinan allí están rodeado por un verdadero aparato burocrático formado por un escriba, un mayordomo, un administrador, un visir, y varios porteros. Que el inframundo de Ereshkigal y Nergal funcione como una ciudad no debería sorprendernos, ya que el fenómeno de la urbanización aparece en el sur de Mesopotamia a lo largo del IV milenio a.C.

${ }^{39}$ En la historia bíblica, Job, hombre un tiempo rico y feliz, es perseguido por Satán, que quiere comprobar su amor y fidelidad a Dios con una serie de desgracias terribles (enfermedad, pobreza, muerte de los hijos): el Omnipotente sabe del acoso demoníaco y Job, que no pierde en ningún momento su fe, será recompensado.
} 
ejemplo, es el que introduce instrumentos útiles a los seres humanos, la agricultura, el fuego, e incluso la muerte ${ }^{40}$.

Por ende: hemos visto que el juego, considerado en sentido amplio, esconde una simbología en la que retorna constantemente la muerte, de la que representa varios atributos. Uno tiene que ver con la posibilidad de engañarla para retardar su actividad, a pesar de que el resultado final no se podrá evitar. Volvamos a los astrágalos por un momento. Hay una imagen que ejemplifica muy bien este concepto del juego como engaño, que ha sido representada en una oinochoe ática de figuras rojas ${ }^{41}$, fechable al $\mathrm{V}$ siglo a.C. (Fig. 5). Aquí podemos notar tres hombres intentos a jugar con astrágalos. Lo peculiar de esta figuración consiste en la representación del momento exacto, en el cual el jugador a la derecha señala a aquello a la izquierda al descubrir su intento de engañar a sus oponentes moviendo la pieza del juego. Es una imagen que refleja significativamente la tendencia del hombre a alterar al fato, intentando imponer su voluntad sobre el destino.

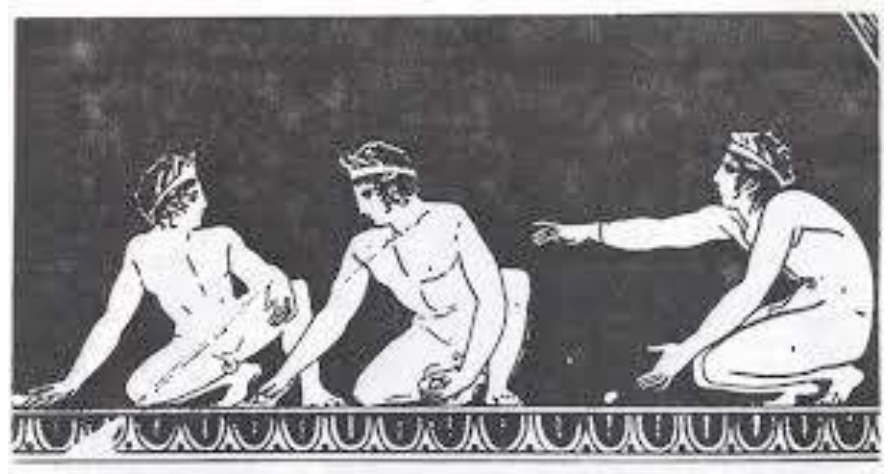

Fig. 5. Jugadores de astrágalos.

Oinochoe ática de figuras rojas.

Quaderni Friulani di Archeologia l/1991.

\footnotetext{
${ }^{40}$ En las mitologías mediterráneas que estamos tratando el trickster no está presente en formas parecidas a otras tradiciones culturales, más bien ha dejado huella en algunos personajes mitológicos o dioses: en Grecia, tiene comportamientos parecidos a los de un trickster Prometeo, el titán bueno que roba el fuego a los dioses para dárselo a los hombres, y, en Mesopotamia, Enki/Ea, que, como hemos visto en nuestros mitos, interviene para salvar a los dioses, es también el dios que ayuda a los hombres cuando sus pares divinos quieren destruirlos: nuevamente, ambos consiguen llevar a cabo sus planes únicamente a través de los engaños a costa de otros dioses. Sobre el trickster, véase Sullivan, L. et al. (2005) "Tricksters". En: L. Jones (ed.). Encyclopedia of Religion. Detroit: pp. 9350-9359, con bibliografía. Comenta el elemento biológico del engaño en la formación de la religión el gran historiador de las religiones Walter Burkert en varios puntos de su The Creation of the Sacred, por ejemplo, en las páginas 23-27.

${ }^{41}$ El oinochoe era una especie de jarra que servía para verter el vino (oĩvos "vino" e $x \dot{\varepsilon} \omega$ "verter"). La cerámica de figuras rojas es una técnica particular usada en la decoración de los vasos, en la que las figuras eran de color rojo sobre fondo negro, y sustituyó la técnica anterior, la de figuras negras, en la que las imágenes eran negras sobre fondo rojo.
} 
Hay algo más. Los huesos de animales que normalmente se utilizaban como astrágalos eran usados asimismo para predecir el futuro, otra dimensión dominada por la incertidumbre, que, por lo tanto, podía ser manipulada.

Otra cosa que hemos visto a lo largo del comentario es que esta conexión del juego, el engaño y la muerte tiene una función cosmológica, es decir, que tiene que ver con el establecimiento de los ámbitos de poder entre las divinidades que, en todas las mitologías antiguas, tienen que delimitar sus poderes y organizar las relaciones entre ellos.

Hay otra característica de la muerte para la que el juego es un emblema perfecto: el azar. La muerte no es solo ineluctable, como nos enseñan los mitos que hemos comentado, eso es, que su llegada no se puede evitar, es también imponderable, fortuita, no se sabe cuándo llega y, sobre todo, a quién va a golpear. Y el juego es, nuevamente, metáfora de ello.

El aspecto aleatorio de la muerte se conserva sobre todo en la iconografía de época romana, que tenía entre sus sujetos favoritos aquel memento mori que hemos mencionado al principio de este estudio.

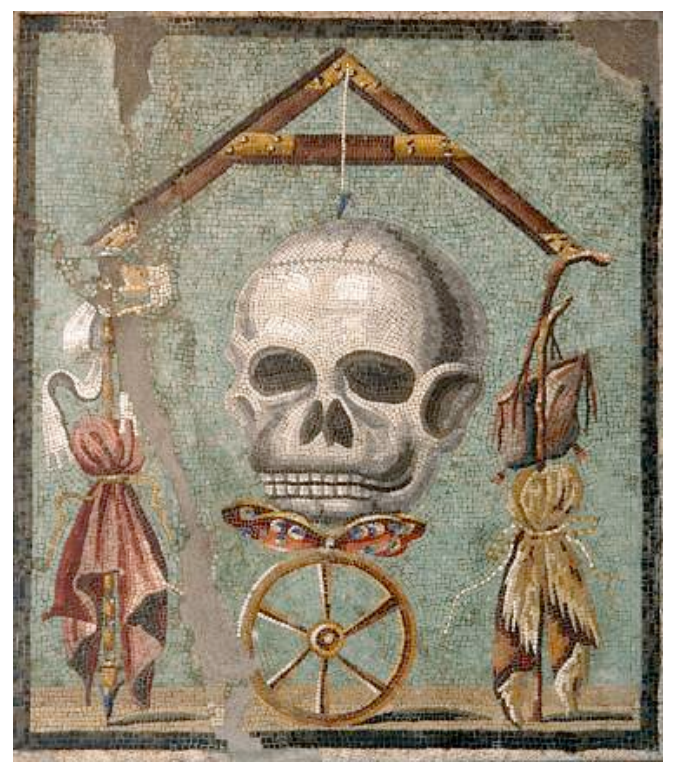

Fig. 6. Memento mori. I sec. d.C. Museo Arqueológico Nacional de Nápoles. Italia
En un fragmento de mosaico hallado en Pompeya (Fig. 6), que es uno de los ejemplos más antiguos de memento mori, la rueda, que es inestable, simboliza Fortuna, y define entonces la vida misma: la Fortuna puede conducir a la riqueza o a la pobreza en vida, aquí representadas por una capa elegante a la izquierda y un pobre atuendo a la derecha. No obstante, estas condiciones 
resultan anuladas y parificadas por la llegada de la muerte, la cual es tan impredecible como lo es la fortuna. De ahí la imagen de la calavera aplastando una mariposa, símbolo de la $\psi u x \grave{n}$, el aliento vital, imagen de una fugacidad existencial y estética (Boardman, 1993: p. 292).

Como hemos visto, durante la Edad Media en Europa este tema recurre y se desarrolla en particular en el esquema iconográfico de la danza macabra difusa en los siglos XIV y XV42: tanto los Triunfos como las Danzas de la Muerte constituyen una versión cristianizada del memento mori romano.

Ahora, hay otra grande civilización antigua, la india, en la que encontramos todo lo que hemos estado comentando. Uno de los conceptos más interesantes de la grandiosa especulación religiosofilosófica del hinduismo es el de lïla ${ }^{43}$, que podemos traducir como "juego": una de las principales divinidades del panteón hindú, Vishnu ${ }^{44}$, crea el universo por juego, y otro de los dioses fundamentales, Shiva ${ }^{45}$ juega al ajedrez con su mujer Parvati (Hiltebeitel, 2005: p. 3263).

Prosiguiendo con este tipo de discurso, resulta que también la danza de la muerte medieval se inserta en este tipo de simbología e interpretación. En las mitologías y religiones antiguas, la danza, un elemento importantísimo en la ritualidad -baste pensar en sus vínculos con el drama y el teatro- entra en la categoría más amplia del entretenimiento. Hemos estado viendo que los dioses de las religiones politeístas son, en sus emociones, muy parecidos a los seres humanos: como seres perfectos a los que nada les falta, se aburren, y muchos mitos, en muchas culturas, hacen hincapié en este "mal existencial" que las sociedades modernas bien conocen, y nos hablan de cómo los dioses aprecian quienes les hace reír y cuánto

\footnotetext{
${ }^{42}$ Volvemos a encontrar el tema de la Rueda de la vida también en un fresco del ya citado Albertus Pictor en el ciclo de frescos de la iglesia de Härkeberga (1480).

${ }^{43}$ Brahmasutra, II, 1, 33

${ }^{44}$ Vishnu, a menudo representado en un estado de profunda meditación, es el dios que sostiene y contiene el universo.

${ }^{45}$ Dios terrible de muerte y destrucción, de liberación e iluminación, con Vishnu y Brahma forma una tríada de divinidades supremas en el hinduismo.
} 
necesitan distraerse ${ }^{46}$. Ambos aspectos están particularmente claros en el mito maya de los gemelos divinos y en la actividad de los dioses del hinduismo. En el primer caso, el juego no es solo el pretexto para cumplir con un castigo divino, sino que es presentado como una implícita necesidad, porque la muerte necesita ser entretenida, lo cual permite al hombre engañarla $y$, en esta peculiar ocasión, derrotarla. Igualmente, el juego de Shiva y de Vishnu representa tanto la acción libre, espontánea, y casi infantil de los dioses que no son necesitan hacer nada pero, al mismo tiempo, encierra la sutil idea del engaño, eso es, que las cosas creadas son solo transitoria y no tienen efectivamente sustancia y validez (de hecho, en la teología hindú, el mundo es maya, "ilusión"), y del azar, o sea, provee una respuesta, si bien parcial y no satisfactoria, al problema del mal en el mundo ${ }^{47}$.

Por otro lado, las tradiciones que conservan muy fuerte el elemento de la danza en sus rituales, la explican con la idea de la igualdad de todos los seres vivientes, sobre todo en determinados momentos, en los que se sentía próximo el fin del universo y, luego, su regeneración: el baile expresa este concepto perfectamente porque en él todos tienen un papel diferente, pero igualmente importante para el éxito de la performance. Esto está particularmente presente en la tradición india, que tiene como uno de sus pilares fundamentales la idea de la regeneración cíclica: algunos rituales descritos en los Veda ${ }^{48}$ ponían en escena dramas en los que se

\footnotetext{
${ }^{46}$ A tal propósito, la mitología helena y la mesopotámica tiene dos episodios significativos. En esta última, en un mito que ya conocemos, el Descenso de Ishtar, el texto deja entender que el ser mágico que Ea crea para salvar a Ishtar ha de halagar a Ereshkigal para levantarle el ánimo. En la versión sumeria, así como en otros mitos, parece que la diosa del más allá está triste por un luto (que nunca es explicado claramente) y hay que mostrarle compasión. En el caso de Grecia, en cambio, es bien famosa la parte del mito de Deméter en el que lo único que hace que la diosa, desesperada por la desaparición de su hija Perséfone, termine su duelo es las risas que le provocan los chistes obscenos de una sirvienta. Para las variaciones en el mito y el siginificado religioso de este episodio, véase M. Olender. (2005) "Baubo". In: L. Jones (ed.). Encyclopedia of Religions. Detroit: pp. 803-804.

${ }^{47}$ Todos las que hemos mencionado son problemáticas difíciles que muchas teologías conocen, pero no es esto el sitio en el que profundizar en estas complicadas especulaciones filosóficoreligiosas. Sobre lila, véase, N. Hein. (2005) "Līla". En: L. Jones (ed.): Encyclopedia of Religion, Detroit. Vol. 8: pp. 5455-5458 y M. Raveri. (2011) "Induismo". En: G. Filoramo et al. Manuale di storia delle religioni. Bari: pp. 306-307.

${ }^{48}$ Libros sagrados de la tradición hindú, una colección de himnos, fórmulas sacrificiales y varios textos religiosos.
} 
representaba el nacimiento, la evolución y la muerte del universo a través de una danza en la que cada miembro de la sociedad era representado; la escena tenía lugar en un espacio sagrado que simbolizaba los tres reinos cósmicos: el cielo, la tierra y el inframundo (Vatsyayan, 2005: p. 2447).

Por ende, nos parece apropiado concluir esta discurso sobre la muerte y el juego con la imagen de Shiva, que ejemplifica perfectamente el tema de este artículo: dios que representa la muerte y la destrucción, en una dicotomía típica del pensamiento religioso hindú, Shiva crea el mundo "por juego", y lo destruye danzando.

\section{CONCLUSIONES}

Una vez llegados al final de nuestra disertación, vamos a retomar lo que hemos dicho para hacer unas reflexiones conclusivas.

Nuestro punto de partida ha sido el análisis del tema iconográfico del juego y la danza de la muerte, muy común sobre todo a partir de la Edad Media y en el arte europeo.

El examen de varias culturas antiguas ha demostrado que tanto el juego como la danza con la muerte estaban presentes en la literatura y en el arte desde tiempos remotos, y que tienen un profundo significado simbólico porque representan la naturaleza misma de la muerte, pues simbolizan su carácter impredecible y misterioso: no olvidemos que de la muerte puede nacer la vida, lo cual tenía que ser bastante impactante para los antiguos. Por eso, el contexto general más adecuado para leer estas historias e imágenes es probablemente el cosmológico, porque tiene que ver con el orden de las cosas, la creación de mitos y la fundación de rituales.

Se podrían hacer muchísimas reflexiones acerca de estas cuestiones. Nos limitaremos a desarrollar un par de puntos. Uno tiene que ver con la continuidad del motivo mitológico e iconográfico del juego y la danza de la muerte que, si bien en formas diferentes, ha sobrevivido a lo largo de la historia humana: en efecto, las historias no se "inventan", sino que se transmiten o evolucionan, como pasa 
por ejemplo con los mitos y los cuentos populares, en un proceso que no es desconocido en la literatura. Igualmente, en el caso que hemos analizado, como se ve sobre todo por el aspecto burlesco que hemos hallado en las representaciones comentadas, el tema de la muerte ha pasado de interesar la mitología, y tener, así, un respiro más amplio y serio, al folklore y la tradición popular. No podemos establecer los canales que llevaron los mitos antiguos hasta la época moderna, aunque, como los hemos encontrado en varias culturas antiguas que no tienen una relación genética entre ellas, es más fácil pensar que se han desarrollados de forma parecida por el imaginario común que distintas culturas desarrollaron acerca de la muerte. Y de aquí vamos al otro, y último, punto.

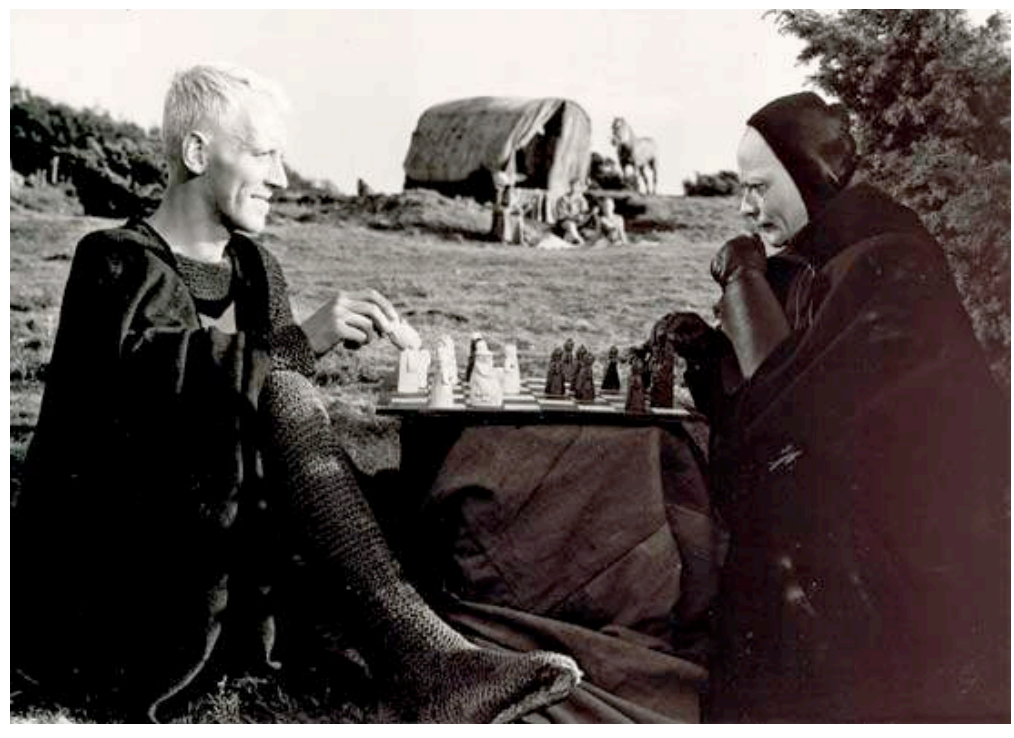

Fig. 7. Max von Sydow y Bengt Ekerot en El séptimo sello (1957). (c) Svensk Filmindustri
Más que todo, este excursus acerca de la muerte nos ha permitido ver cómo ha cambiado con el tiempo la percepción que los hombres tienen de la muerte. A diferencia de hoy, en el pasado, la relación de los hombres con la muerte era mucho más cercana: hemos visto cómo, en algunos mitos, la muerte es representada del todo humanamente, por ejemplo, Ereshkigal. Nuestra actitud hacia la muerte, en cambio, es de indiferencia, como si el ignorar su presencia pueda servir para mantenerla lejos, en una especie de efecto apotropaico.

Sin embargo, las artes, que son más libres en sus manifestaciones, se atreven a tocar temáticas que, como en este caso, infunden temor. 
No solo las películas lo han hecho ${ }^{49}$, podríamos citar incluso la obra de un gran escritor como José Saramago que dedica a la muerte su novela Las interrupciones de la muerte (2005): el cine y la literatura de la misma formas nos presentan a la muerte con la misma espontaneidad y sencillez con la que los antiguos, muy sabiamente, la habían imaginado y tratado.

\section{BIBLIOGRAFÍA}

Black, J. y A. Green. (1992) Gods, Demons and Symbols of Ancient Mesopotamia, Austin.

Boardman, J. (1993) The Oxford History of Classical Art. Oxford.

Burkert, W. (1996) Creation of the Sacred. Tracks of Biology in Early Religions. Cambridge-London.

Burkert, W. (2007) Religión griega arcaica y clásica. Madrid.

Christenson, A. (2007) Popol Vuh. Sacred Book of the Quiché Maya People. Norman University of Oklahoma.

Corrente, P. (2012) Dioniso y los dying gods: paralelos metodológicos. Madrid: Tesis Doctoral. Publicación on-line de la Universidad Complutense de Madrid: http://eprints.sim.ucm.es/18071/

De Nardi, M. (1991) "Gli astragali: contributo alla conoscenza di un aspetto della vita quotidiana attica". En: Quaderni Friuliani di Archeologia: pp. 7588.

Doria, F. (2012) Severe Ludere. Uso e funzione dell'astragalo nelle pratiche ludiche e divinatorie del mondo greco. Cagliari.

Ebersole, G.L. (2005) "Death". En: L. Jones (ed.). En: Encyclopedia of Religion. Detroit. Vol. 4: pp. 2235-2245.

ETCSL $=$ The Electronic Text Corpus of Sumerian Literature

\footnotetext{
${ }^{49}$ No hay solo la película de Bergman. Podemos recordar unas cuantas más, como por ejemplo, el filme mexicano Macario (1960) o ¿Conoces a Joe Black? (1998), esta última basada en la película estadunidense Death takes a holiday (1934), a su vez inspirada por la comedia teatral italiana La morte in vacanza (1924).
} 
Foster, B. (2005) Before the Muses. An anthology of Akkadian Literature, Bethesda.

George, A. (1999) The Epic of Gilgamesh. Londres.

González Zymla, H. (2014) "La danza macabra". En: Revista Digital de Iconografía Medieval. Universidad Complutense de Madrid. Vol. VI (11): pp. 23-51.

Handelman, D. (2005) "Play". En: Encyclopedia of Religion. Vol. 11: pp. 7194-7198.

Hein, N. (2005) "Līlā". En: L. Jones (ed.). Encyclopedia of Religion. Detroit. Vol. 8: pp. 5455-5458.

Hiltebeitel, A. (2005) "Gambling". En: L. Jones (ed.). Encyclopedia of Religion. Detroit. Vol. 5: pp. 3259-3264.

Hornblower, S. y A. Spawforth. (2012) The Oxford Classical Dictionary (eds.). Oxford.

Jacobsen, T. (1976) The Treasures of Darkness. New Haven-London.

Katz, D. (2003) The Image of the Netherworld in the Sumerian Sources. Bethesda.

Olender, M. (2005) "Baubo". En: L. Jones (ed.). Encyclopedia of Religions. Detroit. Vol. 2: pp. 803-804.

Oppenheim, L. (2003) La antigua Mesopotamia. Madrid.

Piccione, P. (1980) "In search of the meaning of senet". En: Archaeology 33 (Julio/Agosto 1980): pp. 55-58.

Raveri, M. (2011) "Induismo". En: G. Filoramo et al. Manuale di storia delle religioni. Bari.

Vatsyayan, K. (2005) "Drama: Indian Dance and Dance Drama". En: L. Jones (ed.). Encyclopedia of Religion. Vol. 4: pp. 2447-2450.

Vermeule, E. (1979) Aspects of Death in Early Greek Art and Poetry. Berkeley.

Sullivan, L. et al. (2005) "Tricksters". En: L. Jones (ed.). Encyclopedia of Religion. Detroit. Vol. 14: pp. 9350-9359. 